\title{
Retraction Note: Cloud computing-based mountain soil characteristics and adolescent anxiety and insomnia management
}

\author{
Mengjiao Liang ${ }^{1}$
}

Published online: 6 December 2021

C) Saudi Society for Geosciences 2021

Retraction Note: Arabian Journal of Geosciences (2021) 14: 1184

https://doi.org/10.1007/s12517-021-07406-7

The Editor-in-Chief and the Publisher have retracted this article because the content of this article is nonsensical. The peer review process was not carried out in accordance with the Publisher's peer review policy. The author has not responded to correspondence regarding this retraction. 